\title{
UMA VISITA A “OLIVEIRA LIMA LIBRARY": CARTAS DE JACKSON DE FIGUEIREDO (11), NESTOR VITOR (1), MACHADO DE ASSIS (6) E ALUIZIO AZEVEDO (1)
}

\section{Antonio Dimas}

Em dezembro de 1974 passei alguns dias na Catholic University of America (Washington, D. C. ) em meu retorno ao Brasil, depois de um ano na Universidade de Illinois, graças a uma bolsa da Fundação Fulbright.

O objetivo era conhecer em detalhes o acervo b:bliográfico de Oliveira Lima (1867-1928) doado àquela universidade e recolher, se possível, algum material que eventualmente pudesse servir na elaboração de meu doutoramento. O interesse principal eram os álbuns de recorte e a epistolografia, de que tinha notícias fragmentadas.

A gentileza do diretor da biblioteca, Prof. Dr. Manuel Silveira Cardozo, permitiu-me esmiuçá-la satisfatoriamente, mas um desânimo ligeiro tomou conta de mim quando vi pela frente 20 gavetas de aço contendo a correspondência do historiador e diplomata pernambucano, pois só dispunha de 5 dias úteis.

Organizadas segundo um critério cronológico e alfabético, essas gavetas armazenam um material epistolográfico de valor inestimável e cobrem um período bastante importante de nossa evolução: 1884 a 1927, aproximadamente.

Nascicio em 1867, Oliveira Lima fez parte da geração que fundou a Academia Brasileira de Letras e porque sobreviveu a muitos de seus colegas (Machado, Veríssimo, Nabuco, Bilac, Aluizio, Romero, Afonso Arinos e outros) teve oportunıdade, como João Ribeiro e Graça Aranha, de estabelecer contacto com a geração seguinte, aquela que haveria de fomentar a alteração cultural posterior a 1920. Oliveira Lima tornou-se, pois, uma espécie de ponie entre dois mundos.

Ao acaso, sem nenhum rigor a princípio, como quem folheia revistas velhas, fui remexenco, aqui e ali, o seu arquivo, seus álbuns de recorte e as gavetas de aço. Deliciosamente desamparado de atitude "séria", fui encontrando pessoas famosas ou obscuras que um dia 
entraram em contacto com o autor de D. João VI no Brasil. Dessa maneira, topei com Machado, Aluizio Azevedo, um camponês agradecido, Fidelino de Figueiredo, Lima Barreto, um médico, Gilberto Freyre, Jackson de Figueiredo, José Veríssimo e outros. Impressionou-me muito a longa correspondência deste, que se mantém em contacto sistemático desde 1899 até cerca de 1909 . Infelizmente, a tinta dessas cartas sentiu muito a ação do tempo. Afora isso, a caligrafia difícil e minha curta disponibilidade não me permitiram um confronto rigoroso das cópias xerográficas com os originais e por isso deixo de oferecer as poucas que trouxe, não obstante sua importância.

A coleta de algumas seguiu-se ao primeiro impacto e nessa tarefa fui auxiliado por Maria Angela Grassi. Na transcrição das cartas, preferi acompanhar rigorosamente o original e só pus entre colchetes aquilo que a ortografia do missivista me deixou em dúvida ou incompleto.

Bahia 14 de Agosto de 1913

Amigo Sr. Dr. Oliveira Lima

Attenciosas saudações

Estou de posse de sua carta de 2 deste mez, e venho agradecerlhe a confiança de um seu pedido a que correspondo com a maior satisfação .

Acabo de falar com Xavier Marquez e tenho sua promessa de que o Sr. será servido no que for possível. (1)

Assim não tardará a remessa dos livros daquelle seu Amigo. Elle agradece penhoradissimo a sua attenção.

Há dias tive o prazer de ler o seu bello livro Carreira Diplomática (2), em que não sei o que mais agrada - se o senso pratico profundo e o conhecimento dessas complicadas questões internacionais, se a limpidez da prosa, das mais simples, das mais portuguesas que se vem escrevendo neste pobre Brasil de escandalos litterarios. Alem

(1) Oliveira Lima escreveu um artigo sobre Xavier Marques - "Jana e Joel" - publicado em $O$ Estado de São Paulo de 15 de março de 1914.

(2) Provável engano.

Sobre Diplomacia, Oliveira Lima tinha publicado até então: História diplomática do Brasil: O reconhecimento do Império. Paris-Rio, Garnier /1901/; e Cousas diplomáticas. Lisboa, A Editora 1908. 
deste livro conheço do meu Amigo um outro sobre a Litteratura Colonial, livro de que me ocupo num ensaio que pretendo publicar

Sem mais, aqui termino fazendo votos para a continuação de uma sympathia que muito me honra e desvanece.

Seu admirador attento.

Jackson de Figueiredo

Rio, 30.6.917

Dr Oliveira Lima

Meu illustre Amigo:

$\mathrm{Ha}$ dias recebi as linhas em que me agradecia a remessa da Brazilea; eu é que fico a dever-lhe a attenção. (1)

$\mathrm{Se}$ o Sr. podesse honrar-nos com algumas paginas, minha alegria seria muito grande.

Ultimamente também enviei para Parnamirim um opusculo editado pela Brazilea: Dos philosophos brasileños. (2)

Esta carta tem como motivo principal um pedido que é o seguinte: aqui se falou muito em dois artigos publicados pelo $\mathrm{Sr}$., em Pernambuco, tratando da nossa situação internacional. Ainda que um pouco duvidoso de alcançar o que desejo, preparo um livro sobre o Pan-americanismo, e quero tratar com largueza do momento internacional sui generis creado pela nossa subserviencia. Preciso destes artigos do Sr. Poderá enviar-m’os?

Aliaz tenho uma carta do Sr., de 1915 em que me promettia alguns dos seus livros. Nunca os recebi.

(1) Brazilea foi uma revista que se editou no Rio e cujo programa era publicar trabalhos que fossem "exclusivamente inspirados nos moldes do puro patriotismo, e [que servissem] á propaganda das nossas criações sociais, artísticas, cientificas e econômicas".

Dirigida por Álvaro Bomilcar, Arnaldo Damasceno Vieira e Jackson de Figueiredo, essa "revista mensal de propaganda nacionalista", disposta a sustentar o "pendão do brasileirismo puro e integral", apareceu em janeiro de 1917 e manteve-se até janeiro-fevereiro de 1918, quando saiu em número duplo: 13-14. Salvo erro, este foi o último número. Localizei-a na Biblioteca Municipal de São Paulo no setor de obras raras.

(2) Artigo do jornalista e escritor argentino Roberto Paterson que assinou Pater. Publicado em espanhol nos números 3 e 4 da Brazilea (março e abril de 1917), o artigo refere-se a Farias Brito e a Jackson de Figueiredo. 
Ultimamente tenho comprado o Pan-americanismo e o sobre a nossa litteratura colonial. Li agora o seu discurso sobre a rev de 1817 na Parahyba, publicado pela "Rev Americana"

Espero enviar-lhe brevemente um livro sobre Farias Brito, trabalho de Nestor Victor que estou editando. (4)

Tambem era intenção minha publicar este anno o meu livro sobre Pascal e a inquietação moderna, mas grandes são as dificuldades e eu, como disse, ando com muito desejo de publicar o que penso sobre a politica sul-americana. Neste assumpto tenho a dizer-lhe que, apezar de pequenas divergencias, tem sido o senhor o meu melhor conselheiro.

Com esta porei no correio um artigo que publiquei n"A Noticia" sobre os allemães no Brazil.

Sem mais, meu illustre e veneravel amigo, subscrevo-me seu sincero admirador

Jackson de Figueiredo

Avenida Pedro Ivo 194 - Casa XI

(3) - Segundo Buito Broca ( $A$ vida literária no Brasil - 1900. 2a ed. rev. e aum. Rio, José Olympio, 1960. pp. 232-233), a Revista Americana não cortejava "o grande público" e visava combater a ignorância recíproca entre os países latino-americanos. "Com o apoio de Rio Branco", a revista apareceu em 1909 e durou dez anos.

O artigo em questão é "Notas à História da Revolução de 1817 de monsenhor Muniz Tavares" e foi publicado em fevereiro de 1917, no fac. V, p. 113.

Embora a Revolução de 1817 tenha-se espalhado pelo Nordeste, Pernambucano foi seu epicentro e não a Paraíba como pode parecer por esta carta.

(4) Em fins de 1917, Nestor Vítor publicou um livro sobre Farias Brito. Dividido em três partes, Farias Brito saiu em edição da Brazilea-Revista dos Tribunais, Rio de Janeiro.

Mais tarde, Nestor Vítor publicou Cartas à gente nova (Rio, Anuário do Brasil, 1924) onde existem duas cartas que comentam a obra de Farias Brito, Uma, de 1918, dirigida a Almeida Magalhães, sob o título "Farias Brito e a reação espiritualista"; outra, de 1919, dirigida a Jackson de Figueiredo, sob o título "A questão social na obra de Farias Brito"

Tanto o ensaio quanto as cartas foram novamente publicadas em dois volumes pela Casa de Rui Barbosa: Obra crítica de Nestor Vítor. Rio, MEC-Casa de Rui Barbosa, 1973. 
Rio, 2 de Agosto de 1917

\section{Meu illustre amigo Dr Oliveira Lima}

Um pouco de alteração na saude de minha Senhora, e o peso de alguns trabalhos, alem dos a que commumente tenho que attender, foram os motivos porque ha mais dias não lhe agradeci a alta generosidade da sua ultima carta e os livros que me enviou. Destes recebi a "Hist. da Rev. de Pernambuco em 1817", e o livro sobre os "Estados Unidos", de que estou a terminar a leitura. A observação é ali em taes profundezas do genio americano, que pude, por minha vez, observar o seguinte, cotejando esta leitura com a que acabara de fazer de um livro de Firmin Roz, muito mais recente, sobre o mesmo povo: o que o livro deste autor contem que valha alguma cousa, em relação ao desenvolvimento yankee, ja o $\mathrm{Sr}$ apprehendera naquella epoca, e com bem mais senso critico. Livro admiravel, e que parece incrivel o tenha escripto o Sr. ha vinte annos! Hei de tratar delle no trabalho que procuro realisar sobre a America, maximé no que se refere às comparações que faz o $\mathrm{Sr}$ do Norte brazileiro com o Sul dos Est. Unidos. Só n'uma cousa divirjo um pouco do Sr.: sou mais optimista em relação ao nosso homem e ao nosso homem e ao nosso meio. O livro sobre a Rev de 1817 ha de ser lido com muito amor Não sei se o Sr recebeu um folheto em que o Barão de Studart faz severa critica de mais de um ponto da narração de Muniz Tavares (1) Se ainda não o tem e the interessa, mande-me dizer, porque lhe cederei o meu com muita alegria.

Eu, aliaz, o li a contragosto pois o autor é, ao meu entender, dos que tiram ao melhor assumpto todo o prazer de conhecel-o, dado que empresta a tudo aquelle tom de erudicção sem unidade, sem visão geral, que Carlyle chamava de "secco como poeira"

$\mathrm{Na}$ Brazilea, que esperará pacientemente, mas com fé, a sua collaboração bondosissima, seja ella sobre o que for e quando bem entender - transcrevo alguns periodos de um dos seus artigos que recebi. Não poderia enviar-me uma tradução que fez (ao que me disseram) de Le feu de J. Barbusse?

Logo que saia o livro de Nestor seguirá o seu exemplar. E verdade que a vida intellectual do Occidente está a afundar-se em maré de fel, e nada se pode fazer nos dominios mais altos do pensamento que interesse seriamente a Europa e os Est. Unidos. Mas tenho-me

(1) Referência provável ao artigo do Barão de Studart - "Três de maio de 1817. O movimento de 17 no Ceará" - publicado pela Revista do Instituto do Ceará, Tomo XXXI, pp. 107-160, 1917 Jackson manifesta-se sobre esse folheto no número de setembro de 1917 da Brazilea, seção "Bibliografia" 
lembrado que ninguem mais capaz do que o $\mathrm{Sr}$., com a sua autoridade, de transmittir ao extrangeiro algumas noções do que foi o esforço de Farias Brito para dotar a America de um pensamento philosophico autonomo, dado que nos Est. Unidos o que fizeram Peirce, James etc, foi a ampliação dos pontos de vista utilitarios da philosophia ingleza, e até no proprio Fr Nietzsche ha, em fulgurantes paradoxos, todo o espirito falso que o pragmatismo nos deu em theoria, com o ar mais moderado. Riem quando falo da autonomia do pensamento de Farias Brito os que não o conhecem e geralmente nada conhecem da historia da philosophia. Em Farias Brito se, sem o saber (posso affirmar-lhe) elle teve ligações, aliaz naturalissimas, com o pensamento christão de Origenes, Malebranche e Forzi (?), principalmente com o dos dois primeiros, se Spinosa, por outro lado, o impressionou muito, o que é verdade é que elle legou á mocidade latino-americana uma lição formidavel de energia moral, e o seu systema, se pode ser considerado dentro, no circulo do pantheismo, o foi de maneira absolutamente original, porque ainda mais do que Malebranche elle foi um reaccionario contra o materialismo que sempre dominou este systema, e poude sustentar-se com fé altamente espiritualista. Pantheista no entender que Deus está em toda a parte, teve o seu logar entre os verdadeiros philosophos dado que não confundiu nunca o Creador que anima com o que foi creado e é obra do espirito e não o espirito mesmo. $\mathrm{Na}$ obra inedita que deixo[u], aliaz incompleta, pois a morte o abateu quando febrilmente procurava levala adeante, elle deixa ver ainda mais clara esta attitude admiravel que só encontra rival em nobreza e dignidade na de Secretan, encarando todo o pensamento moderno de Hegel a Renouvier e Bergson. Se o Sr. pudesse um dia fazer o que aqui lhe lembro, que bem que ajuntaria aos muitos outros tem feito ao nosso paiz! Eu aqui fico disposto a enviar-lhe as obras de Farias.

Recebeu o Sr. o no 7 da Brazilea? Ha dois folhetos sobre dois philosophos brazileiros, um de Xavier Marques e outro do Paterson, escritor argentino. Penso que já lhe enviei ambos.

Bem, meu illustre amigo, vou fazer ponto. Sempre que puder vá enviando-me os livros seus de que acaso puder dispor. Quero ter uma leitura completa da sua obra. Eu muito lucrarei, e talvez Deus me ajude e eu lhe possa pagar na medida do que vale palavra tão humilde como a minha.

Sem mais, creia-me entre os que mais o admiram neste paiz, e muito seu 
Rio, 11-8-917

Meu grande amigo, Dr. Oliveira Lima

Escrevi-lhe ha poucos dias agradecendo o regio presente que me fez de dois dos seus optimos livros. Agora venho importunal-o, mais uma vez, pedindo-lhe uma informação de que muito preciso.

Como talvez o $\mathrm{Sr}$ já tenha notado sinto uma viva, uma insinctiva antipathia pelos Estados-Unidos. Combato-a entretanto o mais que posso como ser que raciocina, e não vive só de sentimento. E assim que procuro instruir-me de tudo que se relaciona com a vida Americana. E preciso notar que fui educado por americanos do norte, mas, negação viva que sou para o estudo das linguas, ainda hoje nada de sei de inglez [sic], e o trabalho quotidiano tem-me impedido de estudar esta lingua, como hei de fazer logo que possa.

Hoje acabei a leitura do seu livro sobre "Os Estados Unidos" e, voltando as paginas, ao retirar algumas notas, tão importantes vi que são as que se referem a John Fiske, que resolvi escrever-lhe esta.

Em verdade se o $\mathrm{Sr}$ puder me indicar alguma tradução francesa ou hespanhola de qualquer das obras do dito philosopho muito the agradecerei. Chamava-o o $\mathrm{Sr}$., naquelle tempo, "o maior philosopho dos Est. Unidos" e eu, do que pude conhecer agora, atravez das paginas admiravelmente claras em que o $\mathrm{Sr}$. expoz as theorias daquelle singular evolucionista, tenho razões para consideral-o bem mais valioso que os mestres agora aclamados do pragmatismo etc. (1)

Assim aqui fica o meu pedido.

Gostei muito mesmo do cap. o Catholicismo e Educação em N America, e que eu sabia não houve até hoje um americanism que prejudicasse a unidade da Igreja, e assim o Sr. previu com justeza a evolução daquella nova fonte de energias catholicas. dia 15 .

Bem, aqui faço ponto. o $8^{\circ} \mathrm{n}^{\circ}$ da Brazilea deverá seguir até o

Carta do seu sincero admirador

Jackson de Figueiredo

(1) “. John Fiske é presentemente o representante mais acabado da cultura americana. / . / Filósofo, foi ele o grande divulgador nos Estados Unidos das teorias darwinianas. ."

Oliveira Lima - Nos Estados Unidos. Impressões políticas e sociais. Leipzig, F. A. Brockhaus, 1899. p. 340. ("Escritores americanos") 
Rio, 3-10-917

Dr. Oliveira Lima

Meu illustre mestre e amigo:

Participo-lhe desde já o nascimento da minha filhinha Regina, no dia 21 do mez passado. E o primeiro filho, e por ahi pode o Sr. desculpar-me que lhe não tenha respondido, com mais pressa, á carta com quie entendeu encher o meu coração de grande e sincerissima alegria. E esta sua carta recebi-a justamente no dia 21 Nella me diz o $\mathrm{Sr}$. do quanto está disposto a fazer um bem do justo renome de $\mathrm{Fa}$ rias Brito. Brevemente enviar-lhe-ei, de uma só vez, tudo quanto me tem sido possivel ajuntar da grande obra de Farias. Até agora não pude encontrar exemplares da 1a. e 2a. parte da Finalidade do Mundo, mas tudo me leva a crer que um amigo vae presentear-me com um volume da 2a. parte e assim, ao Sr., só faltará a 1a. parte da obra inicial que elle, alias, deixou muito emendada no volume que me pertence. Estas emendas foram feitas para a 2 a. edição (que eu hei de dar), e se referem ao naturalismo de que ainda estava imbuido $F$. Brito ha quase trinta annos. o que não é de admirar Já lhe enviei ha dias o livro de Nestor Victor. Este livro determinou o inicio, pelo menos, de uma polêmica entre mim e João Ribeiro (1) Ahi vae o meu artigo; o delle está no "Imparcial" do dia anterior (segunda feira). Como o $\mathrm{Sr}$ mesmo poderá verificar trata-se de um caso de quase má fé, ou, pelo menos, de absoluta falta de sinceridade intellectual. Por isso não calei, apezar do respeito com que sempre tratei aquelle meu patricio e amigo de alguns annos. Aliaz não sei que dizer do João Ribeiro de um anno para cá: ha pouco tempo escreveu um artigo em que chamava o Dr. A. Austregesilo - de escriptor perfeito da lingua (!!!) Que este homem seja um scientista de mérito, um homem de talento, não posso julgar - mas escriptor perfeito da lingua, da lingua que eu falo - é cousa incrivel que diga um sabedor della como João Ribeiro. Mas passemos adeante. mesmo porque no caso em que me tornei seu adversario, tenho certeza de que elle não pode sairse bem.

Apezar do que me promette em relação a Farias, é com muito pezar que encaro a particla do $\mathrm{Sr}$ para os Est. Unidos. O Brazil, cada vez mais, precisa da sua coragem e, depois da guerra, creio que

(1) Por proximidade cronológica, acho que o artigo de Jackson de Figueiredo é "Farias Brito e o Sr. João Ribeiro", publicado em $A$ Notícia do Rio de Janeiro, 2. out. 1917. (Informação colhida in João Ribeiro, bibliografia sobre a sua obra preparada por Antonio Simões dos Reis. Suplemento da Revista do Livro, 4. /Rio/ MEC /1960/.

João Ribeiro pronunciou-se sobre o livro de Nestor Vítor - Farias Brito - em $O$ Imparcial, Rio de Janeiro, 1 out. 1917. 
nossa situação será tão terrivel que viremos a precisar da austera sabedoria da sua palavra. Sei que de onde estiver trabalhará pelo bem da sua terra, mas, se aqui estiver, será muito mais seguro o seu auxílio. Conversando com Barbosa Lima elle me disse indignado que o governo inglez tem feito cmbaraços ao desejo do $\mathrm{Sr}$. de ir a Londres buscar a sua bibliotheca. E o nosso Itamaraty!! Grande força, na verdade, apesar de todas as vergonhosas curvaturas, como esta em que este indecentissimo moleque acaba de reconhecer valimento á black list [?]. Tudo é a Presidencia da República. Ruy não pensa em outra cousa ao fazer-se o porta-voz de toda a miseravel deturpação historica que se vem fazendo em torno desta guerra infernal, producto de 40 annos de fetchismo [?] economico. O antigo zelador dos cachorros de $\mathbf{J}$ Murtinho, o famoso estadista fluminense, a tudo ha de sujeitarnos. para dar o tombo em S. Paulo. E não estou longe de pensar que o conseguirá, porque, alem de estar bipartida, a política paulista tem em Minas um politico habilissimo que, certamente, se puder oppor-se-lhe, há de se oppor. É Wenceslau, homem de gestos timidos, mas de fundo estavel. E digo tudo isto porque só em S. Paulo vejo que ainda ha alguma independencia politica a respeito da situação internacional, pois ainda não desappareceu o "Diario Allemão", e o Dunschee de Abranches não foi repudiado. Como o $\mathrm{Sr}$ sabe este deputado pelo Maranhão é eleito por S. Paulo, como homem das grandes occasic̃es contra o aguia de Haya. Do Dunschee recebi hoje a 3a. edição do Illusão brazileira, (2) Vou ler o livro e ver se consigo jornal onde se possa falar delle. A não ser algumas descomposturas, só o J Oiticica teve do Bittencourt no "Correio da Manhã" licença para dizer alguma cousa do livro com seriedade. É para o Sr ver A Brazilea parecerá exagerada na sua luta contra os portugueses (que são meus avós), mas só parecerá a quem não esteja como eu em contacto com a imprensa do Rio. Esta imprensa é, hoje em dia, absolutamente escrava do commercio portuguez. Os gerentes são geralmente portugueses, o annunciante é portuguez, um terço dos que escrevem é portuguez. Por conseguinte o povo do Rio de Janeiro e o Brazil só lerá o que a Inglaterra, atravez de Portugal, quer que se leia.

Os seus ultimos artigos, se me entristecem pelos males que aponta [sic], me fizeram enormemente orgulhoso, porque nem todos na minha terra estão curvados. E o estrangeiro sabe disto. Tenho-os visto transcriptos na revista do Dr. Zeballos (3), com quem já me correspondi há tempos. Elle prometteu-me escrever sobre Farias Brito, mas não cumpriu o que promettera. Só agora principiei a ler com afinco a

(2) Referência a $A$ ilusão brasileira de Dunshee de Abranches, cuja 1a. Ed. é de 1917. 
Revol. de 1817!! Não me atrevo ao folhetim. Seria ridiculo. Mas não sou pessôa que esqueça deveres com facilidade. Espero que o $\mathrm{Sr}$. me mande mais alguns dos seus livros. Encontrei um traduzido para o hespanhol, e, procurando-o em portuguez não o encontrei! Só existe na livr. Alves, onde não costumo ir porque não sei de cousa mais espontaneamente desorganizada. Afóra o que hei de dizer a respeito das suas ideas sobre politica americana, penso em renderlhe homenagem maior Queria fazel-o agora, neste crepúsculo politico que a grande guerra provocou no coração do Brazil, quando justamente forças enormes se revelam da alma do nosso povo. Queria fazel-o, mas, apezar da minha forte capacidade de trabalho (sem modestia a confesso) penso que me é impossivel. Para não morrer de fome, com a grande familia que tenho (pois alem de minha esposa e minha filhinha, fiquei com uma e uma filhinha de Farias Brito e mais ainda duas orphãs (elle criava 4) já sou obrigado a trabalhar mais do que me permitte a saude, e não tenho materialmente o tempo nem para copiar o tenho escrito Uma luta terrivel em que me debato ha um anno quase, e de que não quero sahir cedendo uma linha. Porque mesmo com os politicos da minha terra poderia eu pôr-me a salvo desta crise, mas prefiro a pobreza e a amargura a entrar na caverna de Cacos (4) Meu lemma pul-o em versos ha muito tempo:

Oh! voz de Deus, a ti somente attendo,

E has de ver, se eu cahir, vencido enfim,

Que hei de morrer, ao menos, combatendo!

Radicalismo absurdo - romantismo - attitude de mocidade dirão - mas assim tem sido, assim será enquanto o meio não apodrecer-me as fibras do caracter E para livrar-me disto, é que combato.

Bem, esta já vai muito longa. Desculpe-me o tom de intimidade com que lhe falo de mim mesmo. Nada valho, mas se de tal forma

Jackson de Figueiredo

(3) O Dr. Estanislau Zeballos, prestigiado homem público argentino, fundou e dirigiu por muitos anos, a Revista de Derecho, Historia y Letras.

Amigo de Oliveira Lima, deste mereceu Zeballos um necrológio - "Um grande argentino" - que Barbosa Lima Sobrinho publicou na Obra seleta do historiador pernambucano (Rio, MEC-INL, 1971. pp. 315-318). O original foi publicado no Jornal do Brasil de 23 nov. 1923. (Cf. Barbosa Lima Sobrinho, org. dos Estudos literários de Oliveira Lima. Rio, Departamento Nacional, 1975. p. 293).

(4) - CACOS: personagem mitológico que roubou algumas cabeças de gado de Hércules e as escondeu em uma caverna. Hércules descobriu o roubo e puniu o ladrão. 
procedo, é sob o impulso da mais sincera sympathya de espirito e de grande admiração que lhe voto. E nestes termos, meu ilustre amigo, aqui faço ponto.

P.S. A Brazilea sae um pouco atrazada. Soffremos um pequeno rombo na nossa pequenissima receita. Mas sempre aproveita a desgraça: este atrazo fez que pudessemos dar já neste numero o seu optimo artigo - (5) victoria nossa de primeira ordem. $\mathrm{O} \mathrm{Sr}$ não avalia a alegria dos meus companheiros.

\section{J.F}

\section{4-10-917}

\section{Meu bondoso Amigo, Dr Oliveira Lima}

Recebi ha dias a sua carta que me trouxe um regio presente: o seu retrato. Não sei como lh'o agradeça. Elle já está honrando a humildade do meu pequeno gabinete, ao lado do de Farias Brito e mais dois ou tres amigos. O seu artigo foi uma victoria de Brazilea e temos recebido parabens pela sua collaboração. Deus permitta que o Sr disponha de tempo e paciencia e não nos abandone.

Junto a esta o meu ultimo folhetim da Notícia. Como verá discorro sobre uma profunda divergencia com o $\mathrm{Sr}$ a respeito do discurso do Sr. Lauro Müller. Em verdade li com surpreza o que escreveu e, com franqueza, penso que foi injusto (1) Eu não discuto o gosto de certas expressões do ex-ministro - mas o discurso se me afigurou verdadeiramente distincto, maximé após o que lá se tem ouvido: Austregesilo \& Compa. A sua crítica me pareceu a de um desaffecto. De minha parte tenho a dizer-lhe que não conheço pessoalmente o Sr Lauro e que, tenho fé em Deus, de jamais vir a precisar delle. Dizem-me até amigos meus que como individuo, isolado, sem função politica, é um egoista. A minha sympathia pelo politico vem de ter assistido de perto a campanha que o derrubou, e sobretudo da revolta que se levantou em mim quando o vi substituido por Nilo Peçanha, a quem, apesar das extemporaneas delicadezas da Tribuna para commigo, considero um indecentíssimo prestigiador. Falo da

(5) Referência a "Necessidade faz lei", artigo de Oliveira Lima publicado pela Brazilea em setembro de 1917, n.o 9.

(1) Oliveira Lima escreve sobre Lauro Müller no Diário de Pernambuco em 6 maio 1917. (Cf. Barbosa Lima Sobrinho, org. dos Estudos literários de Oliveira Lima. Rio, Departamento de Imprensa Nacional, 1975. p. 293).

Jackson escreve sobre Lauro Müller num artigo chamado "O momento" publicado por Brazilea em maio de 1917 Embora sem assinatura, há uma identificação manuscrita - "Jack" - no final do artigo, aparentemente da autoria de Felix Pacheco, a quem pertencia a coleção da revista, hoje em poder da Biblioteca Municipal de São Paulo. 
Tribuna porque sendo este jornal secretariado pelo secretario do Nilo, é, hoje em dia, cousa delle, ao que me dizem. Mas afinal leia o meu artigo onde tenho a certeza de que jamais lhe faltei o respeito nem neguei a grande admiração que the dedico. O mais que pode acontecer é que, dois ou três leitores meus, procurem os seus artigos. Aqui no no Rio fala-se insistentemente que o $\mathrm{Sr}$ virá como deputado ou senador por Pernambuco - ouvi isto até de um filho do José Bezerra. Será verdade? Deus o permitta. A respeito da situação internacional, nem sei o que lhe diga, e creio mesmo que esteja ahi mais bem informado do que eu, tal o numero de boatos desencontrados. Todavia, pelo cuidado nos jornaes e outros movimentos suspeitos, posso affirmar-lhe que alguma cousa de muito grave se prepara com medo. Grave suspeita me veio de dois factos de que fui testemunha: Indo ha dias a um armazem do Loyd fiquei admirado deparanço com um delles abarrotado de metralhadoras. Ora os jornaes não falam disto absolutamente, apesar de não ignorarem este continuo desembarque de armas. O outro facto: ha agora todas as noites, por todo Rio de Janeiro, uma caçada aos chamados sem trabalho, e nas redações (que não noticiam) se diz abertamente que o governo está mandando fazer grandes plantios de cereaes no interior Para que será tudo isto? Será que a Argentina está mesmo preocupando os nossos estadistas? E o que significa a concentração das esquadras alliadas em Montevidéu enquanto nós patrulhamos o Atlântico com couraçados de 18.000 toneladas? Mas não posso comprehender cousa alguma: que significará, por exemplo, a grande modificação que se nota na opinião paulista a respeito dos allemães, a ponto do Diario Allemão se sentir bastante forte para fazer blagues de todo calibre?

Hontem foi o dia do banquete em que o Cons. Rodrigues Alves leu a sua plataforma que deixou em reticencias tudo o que se refere à política internacional, no que fez bem, ao que me parece. Entretanto disseram-me (pois não li) que o Sr. Epitácio Pessoa foi mais affirmativo. em negações!!

Não sei ainda se o Sr. recebeu os livros de Farias que lhe enviei (6 ao todo) Tenho a dizer-lhe que nunca mais recebi jornaes dahi com os seus artigos, alguns dos quais tenho lido no $A . B$.C. que compro por isto. Não sei se já sahiu em S. Paulo o seu artigo sobre o livro de Nestor, a quem já entreguei o cartão.

Amanhã vou ver na Bibliotheca da Camara a colleção do "E. de S. Paulo" O livro do Nestor tem feito aqui algum movimento, e em S. Paulo também.

O "J do Commercio" disse muito bem, respondendo indiretamente a João Ribeiro, com quem hoje me encontrei pela primeira vez, depois do meu artigo e me tratou muito bem. 
Se o $s r$ tem ahi à mão um exemplar do seu livro sobre Litt. Nacional peço-lhe que m'o envie, assim como me mande dizer se só ha em francez e hespanhol o seu trabalho sobre o desenvolvimento intellectual sul-americano (2)

Minha esposa e a pequenita, a primeira por ambas, agradecem as suas bondosas palavras e se recomendam a sua Exma. Senhora.

Eu, um bom amigo, na mesma lucta, não direi infernal, porque ainda tenho muita fé no coração, fé e carinho dos que me estimam.

No dia 12 de Novembro sigo em commissão do Conselho Superior do Ensino até o Sul de Minas e lá ficarei até principio de Dezembro. Assim lhe peço que me escreva para

Lyceu Municipal de

(Via S. Paulo) Muzambinho

Isto se pelo seu calculo sua primeira carta vier chegar aqui depois do dia 12 . E eu a espero ancioso para saber se não ficou zangado commigo.

Adeus! Um abraço do seu

verdadeiro admirador e amigo

Jackson de Figueiredo

Muzambinho, 22 de Nov de 1917

Dr. Oliveira Lima

Meu bondoso amigo:

Aqui, com a maior alegria, recebi sua ultima carta. Sciente do modo digno com que se impõe de todo á minha amizade, perdoandome discordancias de opinião. Sei de como se distancia dos processos vulgares na nossa infeliz politicagem, mas creia que senti deveras sabendo que nada ha de certo a respeito da sua vinda para a Camara ou Senado Eu tinha a certeza de que o Sr. não se conformaria a

(2) - Aparente referências a conferências realizadas por Oliveira Lima em universidades americanas (1912), posterio:mente reunidas, publicadas em inglês e traduzidas para o português: América Latina e América Inglesa. RioParis, Garnier /1914?/ 
taes processos para ser o que tanta gente tem sido, mas andava na illusão de que, em momento tão grave de nossa vida, se teria o bom senso ao menos de refazer aquellas Casas com gente limpa e capaz de trabalhar com seriedade. Eu, se acceitei a commissão porquissima em que estou, foi attendendo primeiramente ao meu estado de saude, que não é bom, e tambem á necessidade de evitar por alguns dis o nevrotismo do Rio de Janeiro, de onde a verdade foi expulsa a pontapés, e o povo, ao que me parece, será levado a todos os excessos, desde o dia em que os submarinos allemães venham a fazer uma ou duas proezas nas nossas costas, se em tal cousa elles pensam.

Tenho comprado o "Est. de S. Paulo" e nunca mais vi nenhum dos seus artigos, nem mesmo o sobre o livro do Nestor Victor. (1)

Não tenho a sua carta aqui presente mas penso que o $\mathrm{Sr}$. me diz que recebeu trez livros do Farias. Se assim é vou reclamar do Correio, logo que o Sr. me escreva, pois, com grande esforço, consegui enviar-lhe todos os livros do Farias, excepto a 1a. parte de "Finalidade do Mundo"

Estou a escrever-lhe um pouco doente. Não pude trazer minha familia, e por isso penso que voltarei brevemente para o Rio, pois, apezar dos bons amigos que tenho aqui, neste recanto singular de Minas - singular porque é um ninho de homens cultos e bons apezar disto, não posso mais viver fóra do meu pequenino meio intimo que está no Rio.

Se não teme a censura, sobre que se tem espalhado tanta cousa, mande-me dizer duas ou trez palavras a respeito de tudo quanto vae acontecendo.

Bem, adeus, meu illustre amigo.

Agradeço-lhe as recommendações para os meus. Recommendeos e á mim a sua digna Esposa e consinta que o abrace o admirador e amigo

Jackson

(1) Em carta de $8 \mathrm{dez}$. 1917, aqui também publicada, Nestor Vítor agradece Oliveira Lima pelo artigo sobre Farias Brito, mencionando explicitamente a data de publicação pelo $A$ Estado de São Paulo: 3 dez. 1917. 
[Rio] 25-10-917

\section{Dr Oliveira Lima}

Meu bondoso amigo:

Quando sahi hoje de casa, pela manhã, e ia por no correio a carta que lhe fiz hontem, encontrei nas portas dos jornaes as noticias da mensagem presidencial pedindo ao Congresso actos de belligerancia effectiva. firmada esta attitude no torpeamento do Macaú, exallemão que levava viveres ao governo francez.

Segui immediatamente para a Camara. Creia que não sahi chorando porque fôra ridiculo em hora tão grave. Ouvi, da gente mais responsavel naquella casa, blagues, pilherias, chalaças. Nem de leve a gravidade que, ao meu ver, requeria um tal momento na vida nacional. Sahi edificado. Eu, ainda creança, vi reformar-se a constituição do Est. de Alagôas no meio de uma troça formidavel. Agora assisti a Camara Federal tomar conhecimento de que vamos entrar na maior catastrophe que já soffreu o Occidente, com a physiognomia de uma pagina dos Maias.

E escute mais esta para que dahi possa orientar-me: o Rio não teve uma vibração! A cidade está tão calma como nos dias de chuva; os cidadãos da republica carregam os embrulhos e os pacotes de bonbon com a mesma santa serenidade. Nas redações arrolhadas ainda foi que senti um certo ar de espanto.. não sei se da mina [?] que está em frente. 30 e tantas pessoas, se tanto, gente quase de pés no chão, percorreram á noite as redações fazendo troça!! Que é que se vae dar? Nas redações corre, com insistencia, o boato de que o Brazil vae mandar 30.000 para Uruguayana. Ninguem explica porque, mas se fala nisto como cousa certa. Causou sensação aqui o desmentido do ministro ingles a respeito da navegação para a Argentina... e em verdade, ao que parece, o ingles não achou de bôa politica o isolar a Argentina.

Desmentindo o que the disse em minha carta de hontem, tenho a communicar-lhe que recebi hoje, pela manhã, seis números do Diario, de que já li os seus artigos. Optimos os que trata [sic] de Nuestra [?] guerra \& Compa. Com menor desenvolvimento eu tratei o assumpto com as mesmas ideas.

Sim: uma das scenas mais intristecedoras de hoje foi a visita do Cons. Ruy ao Ministerio do Exterior Muito tem descido este grande homem. e até creio que ha de chegar a presidente desta pobre Republica. O exercito, na maioria, contrario a intervenção armada, 
ainda não piou. Estou ancioso por ler os seus artigos a respeito do novo passo Adeus!

Um abraço do seu admirador

e amigo

P.S. De dois em dois dias hei de lhe dar informações do que se vae passando por aqui, de caracter menos jornalistico.

Dia 26

Agora, pela manhã, acabo de receber um cartão do Sr . previnindo-me de que recebeu 3 volumes da Finalidade do Mundo. Por minha vez previno-o que enviei 6 - alem da 1a. 2a. e 3a. partes da Finalidade, livros que o $\mathrm{Sr}$ recebeu, enviei mais os seguintes: $A$ verdade como regra das acções; $A$ base physica do espirito; $O$ mundo interior Mandei tambem um volumesinho do Paterson e outro de Xavier Marques. O Sr. pode reclamar no correio.

[Carta aparentemente truncada no final, pois não consegui localizar a última página.]

Muz. 26 de Nov de 1917

Dr. Oliveira Lima, meu bondoso amigo:

Ainda aqui me encontro, não só finalizando os trabalhos da commissão como tambem em proveito de minha saude, numa especie de retiro espiritual. Porque, em verdade, todas as noticias que me chegam do Rio são aborrecidas, parecendo que ainda nada está assentado no pensamento do governo. Ha dois ou trez dias li um artigo seu no "Est. de S. Paulo" sobre a C. [achoeira] de P. [aulo] Affonso (1).

Esta cartinha é para recommendar-lhe um livrinho que nesta data ponho no correio - A mulher no Brasil, do $\mathrm{Sr} \mathrm{M}$. Pinto Pereira, moço pobre que aqui vive como professor Escrevi sobre este livro no $10^{\text {9 }}$ numero da Brazilea (2) e disse delle o que de facto penso -

(1) Segundo Barbosa Lima, que recolheu esse artigo na Obra seleta de Oliveira Lima (Rio, MEC-INL, 1971. pp. 427-438), "Um passeio a Paulo Afonso" foi publicado pelo $O$ Estado de São Paulo em 4, 12, 21 e 22 de nov. de 1917. (Cf. Estudos literários de O. Lima, org. por Barbosa Lima Sobrinho. Rio, Departamento de Imprensa Nacional, 1975. p. 293.).

(2) Jackson manifestou-se sobre o livro em longa resenha, onde confessava que o "movimento feminista.. é para mim fenômeno cujo fundo está na anarquia contemporânea de todo voltada para as preocupações utilitárias mais baixas." (Brazilea, 1917, out. n.o 10) 
isto é - não gosto do escriptor propriamente, não supporto a sociologia á maneira do autor [?], mas penso que é realmente louvavel o seu esforço.

Se o Sr. puder escreva-lhe algumas palavras e pode mesmo envial-as para mim no Rio, como o velho endereço: Av Pedro Ivo 194 - casa XI.

Eu devo partir daqui no dia 2 ou trez de Dez.

E adeus!

Recommende-me a sua digna Esposa e deixe que o abrace o seu sincero admirador e amigo

Jackson

Muzambinho, 6-12-917

Dr Oliveira Lima, meu excellente

Amigo:

Estou ás vesperas da minha volta para o Rio. Tocarei ainda em Alfenas onde vou fazer uma conferencia, mas creio que, ainda assim, estarei no Rio até o dia 15 do corrente.

Hoje registrei no correio um volumesinho para o Sr.; contem uma ligeira palestra com o publico muito amigo desta cidadesinha original (1) - de que já falei duas vezes na Brazilea com absoluta sinceridade: em uma pagina sobre o Lyceu e em outra sobre Julio Bueno que aqui vive. (2)

Mais uma vez lhe peço algumas palavras de agradecimento ao Pinto Pereira que o admira muito. Ainda hoje em casa delle estivemos a ler algumas paginas do seu trabalho sobre D. João VI.

(1) § Referência a "Pelo Brasil", conferência pronunciada em 15.11.917 em Muzambinho, M.G. e publicada com o mesmo título pela tipografia do jornal $O$ Muzambinho.

Localizei um exemplar na Biblioteca Municipal de São Paulo.

(2) Segundo Jackson de Figueiredo, ulio Bueno foi professor e jornalista no sul de Minas. Nascido em Campanha (M.G.) em 1815, Jackson veio a conhecê-lo "em Muzambinho como o filósofo da terra" (Brazilea, maio de 1917, n0. 5.). 
Se o Sr. ainda tem algum exemplar do seu livro sobre os "Est. Unidos", livro que não existe á venda, m'o envie.

O motivo principal desta cartinha é beijar-lhe as mãos pelos seus dois excellentes artigos sobre Farias Brito que tanto o "Estadinho" como o "Estado" de S. Paulo tem publicado. (3) Elles concorrerão poderosamente para que se faça em redor de Farias a athmosphera de respeito que incontenstavelmente merece.

Bem, adeus!

Recommende-me a Exma. Sra.

e deixe que o abrace seu amigo

e admirador

Jackson

Rio, 5 de Maio de 1918

Meu bondoso amigo

Ha muito tempo mesmo que não recebo uma linha sua. Antehontem porem, recebi alguns numeros de jornal com os seus admiraveis artigo. Tenho visto alguns delles transcriptos aqui no A.B.C. revista politica que, certamente, o $\mathrm{Sr}$ recebe. Tambem é o $\mathrm{Sr}$ o unico homem que ainda ousa dizer algumas verdades a este singularissimo paiz. Algumas vezes eu o faço tambem - mas que sou eu, quem se dá ao trabalho de ouvir-me? Ainda não terminei a minha campanha em prol da honra do meu Estado Natal. Não foi pouco o que conseguimos até agora, e ainda tenho esperança de que sejam maiores os resultados desta reacção. Todavia, ao que me parece, é quase certo que se vae dar immunidades parlamentares a um homem que, reconhecidamente devia estar na cadeia ha muitos annos. Eu estive na Camara em formação. A impressão é esta: a céva, como se faz ahi no Norte, para os porcos mais ruins. Eu estive bastante adoentado. Fui forçado mesmo a ficar alguns dias em Petropolis. Não estou bom,

(3) Segundo o Nestor Vitor da "Coleçāo Nossos Clássicos" da Editora Agir (Rio, 1963. Org. por Tasso da Silveira), Oliveira Lima publicou dois artigos sobre Farias Brito em $O$ Estado de São Paulo: nos dias 3 e 10 de dezembro de 1917.

Neusa Dias Macedo (Bibliografia de Manuel de Oliveira Lima. Recife, Arquivo Público Estadual, 1968) não registra esse artigo. Barbosa Lima Sobrinho também não. 
mas já não me sinto tão abatido. Em meio desta luta que me rouba horas preciosas ao meu trabalho intellectual, não me tenho, de todo, furtado a este outro mundo. Assim tenho copiado quase todo o meu livro sobre Pascal (1) e penso que entrará no prelo até o fim deste mez. Ha dias conversava com Annibal Freire (2) quando fui apresentado a um moço, o Sr. Assis Chateaubriand (3), que esta fazendo um bom nome na nossa imprensa, e falou do $\mathrm{Sr}$ com muita admiração. Fiquei sabendo do seu methodo de trabalho e a invejal-o nisti, como em tantas outras cousas.

Os meus vão passando bem, e se lhe recommendam a sua Exma. Senhora.

$\mathrm{Eu}$, meu amigo, o abraço com respeito e amor

Jackson

Livraria Catholica

Rodrigo Silva 7

Rio

Rio, 8 de Dezembro, 1917

Meu bom amigo Sr Dr Oliveira Lima,

Muito lhe agradeço o tão intelligente e benevolo artigoUm philosopho brazileiro que teve o senhor a bondade de escrever a proposito do meu ensaio sobre Farias Brito, artigo publicado na edição da noite do "Estado de S. Paulo", a 3 do corrente, e que hontem tive occasião de ler. (1) Nós, os amigos de Farias Brito, estamos informados pelo Jackson de Figueiredo [sic] de que com este trabalho o illustre patricio apenas enceta o esforço que tenciona fazer, principalmente no estrangeiro, pela divulgação da obra daquelle nosso insigne pensador. Não preciso dizer-lhe, todos fazemos votos porque não demore muito o momento opportuno a tão generoso emprehendimento. As circumstancias da sua vida, meu bom amigo, tem feito com que no estrangeiro

(1) Referência a Pascal e a Inquietação Moderna. Rio, Ed. do Centro D. Vital $/ 1922 /$.

(2) Aníbal Freire (1884-1970) nasceu em Lagarto, Se. Foi jornalista advogado, político, professor e ministro do Supremo Tribunal.

(3) Fransico de Assis Chateaubriand Bandeira de Melo (1892-1968) nasceu em Umbuzeiro ( $\mathrm{Pb}$ ) e faleceu em São Paulo (S.P ) Bacharel em Direito pelo Recife, tornou-se influente jornalista e proprietário de ampla cadeia de jornais, revistas e televisão.

(1) Ver carta de Jackson de Figueiredo de 6 /dezembro/ 1917, nota 3. 
tenha o senhor prestado ao paiz os mais consideraveis de seus serviços como homem de letras e pode-se dizer sem contestação plausivel que nenhum intellectual os prestou, nestes tempos, comparaveis aos seus, principalmente na extensão que elles puderam alcançar. Mas, si lhe fôr permittido dar continuidade a esses trabalhos pondo em foco a obra de Farias Brito num momento em que o mundo possa prestar-lhe a devida attenção, estou que com isso aproveitará a melhor das opportunidades que até aqui se lhe tem offerecido para revelarnos lá fóra naquillo que ja pode patentear a nossa existência como povo propriamente dito.

Aproveito a occasião para expressar-lhe o pezar que tive em não ter sabido antecipadamente de sua partida, quando se foi agora daqui do Rio, pois era minha intenção retribuir-lhe a visita que gentilmente me fez.

Peço-lhe apresentar, da minha parte, respeitosos cumprimentos a Mme. Oliveira Lima, e que, com a reiteração dos meus agradecimentos, um affusivo aperto de mão de quem é

Seu amigo e admirador

Nestor Vitor

Rua 18 de Fevereiro, 71

Botafogo

(Machado)

Rio de Janeiro, 18 de Novembro 1904

Meu prezado e illustre amigo

Acabo de receber a sua carta, referindo-me o effeito que lhes

produziu a noticia da morte da minha boa e amada Carolina, e trazendodo-me as condolencias de ambos. Tambem eu não contava com tal golpe. A doença era pertinaz e o estado de abatimento grande, mas estava longe de suppor que, saindo de casa para a Secretaria, viesse achal-a prostada na cama. Pouco depois do meio dia, manifestava-se uma forte hemorhagia, que lhe fez perder os sentidos. Quando voltou a si quizeram mandar-me chamar, tiveram de obedecer á sua vontade contrária, por me não assustar, disse ella. Vinte e quatro horas depois, expirava. (1)

(1) "A vinte de Outubro de 1904, com setenta anos de idade e trinta e cinco de casada, falecia Carolina." (Lúcia Miguel-Pereira, Machado de Assis (Estudo crítico e biográfico). 2a. ed., SP, Cia. Ed. Nacional, 1939. p. 293). 
Diz-me bem, em termos proprios, o que esta dor foi para mim, e o que vae ser a minha vida, se vida se pode chamar o resto dos meus velhos dias. Sinto-me acabado. Vivemos casados 35 annos, e eu sempre imaginei ir antes della.

Creio, creio nos sentimentos de pezar que, em nome da Exma. Sra. D. Flora e no seu, me envia neste momento cruel da existencia. Creio e agradeço-os, como sendo dos remedios moraes que ainda podem trazer algum animo a um enfermo desenganado de si mesmo e meio morto de solidão. Peço-lhe que apresente a sua distincta consorte os meus respeitos, e para si envio-lhe um abraço de

$$
\text { Amo. velho e agradecido }
$$

Machado de Assis

(Machado)

Rio de Janeiro, 4 de Dezembro de 1904

Prezado am? Dr. Oliveira Lima,

Creio que a minha carta, em resposta á sua de pesames, o haverá achado no Engenho que deixou indicado. Esta vae com o mesmo destino, e espero tenha igual encontro.

O objecto agora é agradecer-lhe as finesas que me fez, em meio da sua viagem; refiro-me ao seu gentil artigo (1) á cerca do meu último livro, Esaú e Jacob Todo elle, de principio a fim, manifesta o seu espirito tão longamente benevolo, ao mesmo tempo que ancioso de buscar a verdade e definil-a. Succede commigo o que succederá com os que the merecerem sympatia particular: esta dominará o julgamento.

Muitos me falaram em tal trabalho, e eu cá o tenho entre minhas melhores lembranças.

Quisera dizer-lhe mais que isto, mas confesso-lhe que estou ainda sob a ação da minha desventura. Minha mulher, se pudesse ter lido o artigo, sentiria o mesmo que eu; mas nem sequer leu o livro, posto me dissesse que o leria [ilegível]; apenas leu algum trecho, o que

(1) "O último romance de Machado de Assis" foi publicado na Gazeta deNoticias do Rio em 21 nov. 1904.

Barbosa Lima Sobrinho recolheu-o nos Estudos literários de Oliveira Lima. (Rio, Departamento de Imprensa Nacional, 1975. pp. 29-32). 
me foi confirmado por uma de suas amigas, a quem ella o confessou como prova do estado em que se achava.

Adeus, meu caro $a m^{0}$ e confrade. Novamente the agradeço o seu fino estudo. Peço-lhe que apresente os meus respeitos à Exma. Sra. D. Flora, e disponha do

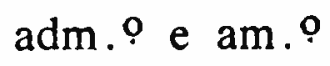

\section{(Machado)}

Rio de Janeiro, 21 de Abril de 1905

Meu caro am. .9 e collega

Recebi o seu voto para o segundo escrutinio da nossa eleição academica, Vi os tres motivos do voto, e são os que todos contavamos da sua parte. Acabo de receber igualmente o do Nabuco, que vae tambem ao mesmo Souza Bandeira. (1)

Talvez a eleição nova se faça ja na casa da Academia que, como sabe, é parte do edificio da praia da Lapa, onde estão alojados o Instituto dos Advogados e a academia de Medicina. Faltava a mobilia, mas posso dizer-lhe, ainda em reserva, que ja a vamos ter, graças a boa vontade do Seabra (2)

Os seus amigos daqui ficamos com os olhos na carreira que continua, certos de que corresponde, agora como antes, á confiança de as suas victorias, que serão de nós todos.

Deixe-me agradecer-lhe o exemplar da sua bella conferencia realizada no Instituto Archeologico do Recife, á cerca da Vida diplo-

(1) Sousa Bandeira foi recebido na ABL em 10 ago. 1905 por Graça Aranha.

(2) Machado menciona três vezes o Ministro J.J. Seabra nas cartas que foram recolhidas pela Obra completa da Ed. Aguilar, Rio, 1962, vol. III (18 jul. 1900, carta a Lúcio de Mendonça; 15. fev. 1904, carta a Mário de Alencar; 24 jun. 1905, carta a Joaquim Nabuco).

Todas as três apontam a boa vontade do Ministro para com a ABL, mas é na última que Machado faz-se mais explícito: "A cerimônia 「de posse de Sousa Bandeiral será na casa nova e própria, entre os móveis que o Ministro do Interior, o Seabra, mandou dar-nos."

Fundada em 1896, a Academia, "graças à iniciativa do Ministro Seabra, passa a ter sede própria, ocupando uma parte do Silogeu Brasileiro", em 1905, explica Brito Broca em $A$ vida literária... 2a. ed. rev. e aum. Rio, José Olympio, 1960. p. 59. 
matica (3) Agradecer-lh'a e felicital-o por ella. Tem o tom proprio do genero e da materia, a boa distinção do que cabe á diplomacia de hoje e do que lhe attribue ainda a parte do pessoal que a não vê por outros olhos se não os do futil; enfim, a definição do que foram entre nós Penedo e Itajubá, entre outros.

Peço-lhe que apresente á Exma. Senhora D. Flora os meus respeitos, e não esqueça este velho acabado, ainda admirador dos seus vivos e solidos talentos, que lhe manda um

$$
\text { abraço mto. apertado, }
$$

Machado de Assis

\section{(Machado)}

Rio de Janeiro, 20 de Novembro de 1905

Meu prezado amigo,

Recebi e cordialmente lhe agradeço o cartão postal de 16 de Setembro, em que junta as suas finesas, ás que os amigos da nossa Academia me fizeram. Faltava a sua palavra para completar a bondade de todos. No ponto da vida a que cheguei, e no meio da grande solidão moral em que vivo, os favores litterarios são ainda a melhor consolação e o mais forte esteio. Naquella noite não agradeci de palavra o que me fizeram e disseram, não só porque nunca me coube

improvisar nada, e apenas sei ler atado e mal, mas ainda porque não poderia falar, se soubesse tal foi a minha commoção. Em verdade, a manifestação foi calorosa, as vozes que me falaram amigas e verdadeiras, daqui e de fora, novas e velhas. Além disso, a falta da minha pobre esposa, que sentiria grande alegria, como sempre teve em tudo o que era benevolencia para mim, fez crescer a minha commoção. Tive de ficar calado, mas todos me comprehenderam e me perdoaram o silencio. (1)

(3) Conferência realizada em $22 \mathrm{dez} .1904$ no citado Instituto. Publicada pela Tipografia do Jornal do Recife em 1904. Incluída, posteriormente, em Cousas diplomáticas, editado em Lisboa, A Editora, 1908. (Cf. Neusa Dias Macedo, Bibliografia de Manuel de Oliveira Lima. Recife, Arquivo Público Estadual, 1968).

(1) Em abril de 1905, Joaquim Nabuco enviava um "ramo de carvalho de Tasso" para Machado de Assis. A homenagem vinha de Londres, por intermédio de Graça Aranha, que se encarregou de fazer a oferta durante a posse de Sousa Bandeira na Academia Brasileira de Letras, ocorrida a 10 de 
Houve recentemente uma eleição na Academia para a vaga do José do Patrocínio. Foi eleito o Mario de Alencar O seu voto deixou de ser lido na sessão, e aliás era o que primeiro recebi; nessa mesma tarde, porém, minutos depois da sessão, fui aos jornaes completar a noticia da eleição com a declaração da omissão involuntaria, do nome do academico e do nome do votado. O Domingos Olympio, dado com 9 votos, ficou assim com 10. O Alencar foi escolhido com 17 Se leu os jornaes viu tudo isso. E terá visto mais, porque o resultado da eleição não agradou a todos, e a manifestação de desagrado durou alguns dias na imprensa.

Que trabalho tem entre mãos? Não é preciso dizer-lhe que se não captive totalmente á diplomacia e intercalle aos cuidados do protocollo cuidados puramente litterarios. Dê-nos daquelles esciptos a que o seu espirito sabe ir com tanto brilho. Soube ha dias, por uma referencia de jornal, que tem escripto cartas para o Estado de $S$ Paulo (3) Não o tenho aqui. De uma dessas cartas vi transcripto um trecho relativo ao Ruy Barbosa e á conveniencia de o mandar representar o Brazil em congresso internacional. Do que escreveu

agosto de 1905. (A carta de Nabuco a Graça Aranha está nas Obras completas de Machado de Assis. Rio, Aguilar, 1962. Vol. III, p. 1074).

Machado, po sua vez, mostou-se extremamente comovido e outras cartas suas expressam essa satisfação. Ver, p. ex., na edição acima citada, seus agradecimentos a Joaquim Nabuco (p. 1075) Ver também outra carta de 2 out. 1905 na Correspondência de Machado de Assis com Magalhães de Azeredo, ed. preparada por Carmelo Virgilio. Rio, INL. 1969. p. 267

ç ê....,v, etaoin shrdlu cmfpúâ vbgçqj xzíaá etaoin shrdlu cmfpâú vbgçqj zíãòá

(2) A eleição de Mário de Alencar parece ter sido um momento de fraqueza de Machado de Assis, talvez movido pelo desejo inconsciente de homenagear o pai do candidato, José de Alencar.

Domingos Olimpio foi seu concorrente e tinha vários pontos a seu favor: diretor da revista Os Anais e autor de Luzia-Homem.

Brito Broca ( $A$ vida literária no Brasil - 1900. 2a. ed. rev. e aum. José, Olympio, 1960. pp. 59-61) chega a falar em "cabala” e “"panelinha' de Machado de Assis trabalhada pela influência de Rio Branco". E menciona também que Machado fora acusado publicamente de haver omitido o voto de Oliveira Lima.

Omissão deliberada ou não, o importante é que o voto de Oliveira Lima não fora decisivo (Mário teve 17 votos e Domingos Olímpio teve 10) e, mais importante ainda, é a limpeza de procedimento de Machado para com Oliveira Lima.

Em algumas cartas desse período, publicadas nas Obras completas (Rio, Aguilar, 1962. Vol. III), Machado comenta discretamente as eleições antes de se realizarem. A mais incisiva, nessa série e sobre essa candidatura, é uma de 29 ago. 1905, dirigida a Joaquim Nabuco: "Na Academia não há nem deve haver grupos fechados"

(3) Segundo Fernando da Cruz Couvea (in Oliveira Lima - Obra seleta. Org. por Barbosa Lima Sobrinho. Rio, MEC-INL, 1971. p. 197) Oliveira Lima "inicia a 10 de outubro a sua colaboração em $O$ Estado de São Paulo" 
naquelle jornal sobre Diplomacia de Carreira ja lhe falei quando respondi á sua carta de 23 de junho. Eu, meu caro amº, não me sinto com o gosto de outrora nem igual disposição. Tenho no prelo, em Pariz, uma colleção de pequenos trabalhos, alguns ineditos, outros impressos ja, que o Garnier edita. Não disse isto ainda a ninguem, a não ser vagamente, creio que ao Verissimo. Escreveria outra cousa, se pudesse, mas a edade, e mais que ella o estado morbido não me consentem grande esforço. (4)

Os amigos aqui vão bem. Reunimo-nos no Garnier, às tardes, e ás segunda-feiras fazemos sessão na Academia; interrompemos estas agora até o dia 30 de Novembro, que é o dia da eleição de mesa e férias. Os trabalhos recomeçarão em Maio.

Vá relevando estas emendas de palavras, com o desalinho da escripta e a ruim letra, que sempre foi má e está peor. Oxalá não contribua para tudo isso o estados dos olhos, que não me parece bom, mas deixemos tristezas novas. Justo é que os filhos da cidade vão deperecendo, quando ella vae remoçando. Não digo desta, porque hade saber tudo, e terá lido as noticias da inauguração da Avenida Central; mas por muito que leia e creia, não imaginará a mudança que foi e está sendo, nem a rapides do trabalho. Mudaram-me a cidade, ou mudaram-me para outra. Vou deste mundo, mas ja não vou da colonia em que nasci e envelheci, e sim de outra parte para onde me desterraram. (5)

Adeus, meu presado amigo. Peço-lhe o favor de apresentar á Exma. Senhora D. Flora os meus respeitos. Disse-me a 23 de Junho que nem um nem outro tem passado muito bem. Folgarei que estejam restaurados, e se [?] ainda os vir aqui, em caminho para outro pouso. Adeus, meu caro amigo, muitas saudades do

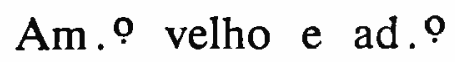

Machado de Assis

(4) Em 1906 saíam As relíquias da casa velha de Machado, cujo "estado mórbido" deveria estar bem acentuado uma vez que na "Advertência" inicial, o autor publica, em primeira mão, o seu famoso soneto "A Carolina". (Cf. Bibliografia de Machado de Assis - J. Galante de Souza, org. Rio, INL, 1955. p. 110).

(5) Referência às profundas alterações urbanas por que passou o Rio de Janeiro na primeira década deste século, estando na Presidência da República o Conselheiro Rodrigues Alves e na Prefeitura do Distrito Federal o Dr. Pereira Passos. 
Rio de Janeiro, 5 de Fevereiro de 1906.

Meu prezado amigo,

Recebi a sua carta de 20 de Dezembro no fim do mez passado e só agora the respondo. Não deite a demora á conta da vontade. Já nessa mesma carta me diz, com a benevolencia que sempre me mostrou, escrevendo ou falando, que não me queria mal pelo silencio, e até indica algumas causas possiveis deste. Todas são verossimeis, alguma é verdadeira, e nenhuma parte do coração.

Tenho noticias suas pelo Verissimo e pelo Rodrigo Octavio. (1) Agora sei pela sua carta que melhorou de recentes incommodos, assim como a Exma. esposa e a ambos envio as minhas felicitações. Pelo que me escreve está concluida a missão que o levou a Caracas, (2) e espera agora uma remoção que ainda não sabe para onde seja. Se no intervalo vier ao Brasil não é preciso dizer o gosto que dará a todos os seus amigos, alguns dos quaes ainda tem o centro no Garnier, posto que espaçadamente, porque o Verissimo e o Graça estão passando o verão em Petropolis. Talvez assista á recepção do Mario, que não será antes de tres ou quatro meses; responder-lhe-ha o Coelho Netto. (3) A Academia vae abrir a vaga de Pedro Rebello. (4) Venha e verá o Rio com as suas roupas novas. (5)

Vejo que o seu $D$. João V'I está crescendo e sairá maior do que esperava. Tanto melhor, meu amigo; o prazer de o ler será tambem maior E assumpto que podemos dizer inedito; esperava historiador que o comprehendesse e trabalhasse bem. Vamos ter a physionomia real daquelle principe que, vindo aqui fundar "um novo imperio", co-

(1) Rodrigo Otávio (1866-1944) foi da roda boêmia do fim-do-século e ajudou na fundação da $\mathrm{ABL}$, cujos trabalhos preparatórios deixou documentado. Ministro do Supremo Tribunal Federal, foi também Sub-secretário das Relações Exteriores de Epitácio Pessoa e professor na Faculdade de Direito do Rio de Janeiro.

(2) Oliveira Lima participou das negociações sobre limites territoriais com a Venezuela, onde ficou de maio de 1905 a junho de 1906. (Cf. Obra seleta, og. por Barbosa Lima Sobrinho. Rio, MEC-INL, 1971. p. 197.

(3) Mário de Alencar tomou posse na ABL em 14 ago. 1906 e foi recebido por Coelho Neto.

(4) Pedro Rabelo: cronista, jornalista e polemista, fez parte da roda boêmia do fim de século. "Faleceu com apenas 37 anos no Rio de Janeiro, a 27 de dezembro de 1905. Foi o membro da Academia que morreu moço. Não teve elogio acadêmico, porque seu sucessor, Heráclito Graça, tomou posse por carta." (Cf. Raimundo de Menezes, Dicionário Literário Brasileiro. SP., Ed. Saraiva, 1969. Vo. IV.).

(5) Referência às renovaçōes urbanas que alteraram a fisionomia do Rio no começo do século. 
mo elle mesmo disse, tão particularmente contribuiu para a nossa independencia. Venha o seu livro; eu, ha dias, - um destes dias da minha vida solitaria, - fugi á realidade da hora e do logar, relendo algumas das suas interessantes paginas sobre o Japão, (6) e ainda uma vez me deliciei com ellas.

Eu nada tenho. Reuni alguns retalhos ineditos e impressos, que o Garnier faz sair em volume, (7) e é tudo. Tinha um livro em projecto e inicio, mas não vou adeante. Sinto-me cansado, estou enfermo, e falta-me o gosto. Adeus, meu amigo, não esqueça este velho amigo, ainda não perdeu a faculdade de admirar Peço-lhe que apresente os meus respeitosos cumprimentos a Exma. Senhora D. Flora, e receba para si um grande abraço.

Machado de Assis

15 de Novembro 1907

Meu caro am e confrade

Recebi a sua carta de hontem, e aqui lhe respondo. O nosso collega Arthur Orlando tambem me procurou hontem para me communicar que havia levado o discurso a V. Ex., a quem folgo de dizer, em nome de todos nós, cabe muito bem recebel-o na Academia. (1)

Em conversação perguntei ao Orlando se, devendo ser recebido daqui a poucos dias o Augusto de Lima, (2) e tendo sido recebido este mesmo mes o Jaceguay (3), não havia algum inconveniente na recepção delle logo depois de ambos. A tarde, em sessão academica, communiquei aos nossos companheiros o que se passára. O Augusto de Lima tambem está com o discurso prompto e entregue ao Medeiros

(6) Referência a No Japão: Impressões da terra e da gente. Rio, Laemmert, 1903 .

No necrológio de Aluizio Azevedo, Oliveira Lima diz: "Eu nunca pudera compreender porque Aluizio não publicara o seu livro sobre o Japão que me diziam pronto. Nunca lhe quis tocar no assunto por uma natural delicadeza [ . ]. Percebi agora que o Japão escapara à penetração de seu espírito ou, por outra, só a este aparecera sob um aspecto caricatural." (Artigo recolhido por Barbosa Lima Sobrinho nos Estudos literários. Rio, Departamento de Imprensa Nacional, 1975. p. 236) .

(7) Aparente referência às Relíquias da casa velha, cuja 1a. ed. é de 1906.

(1) Oliveira Lima recebeu Artur Orlando na Academia Brasileira de Letras em 28. dez. de 1907. 5 dez. 1907

(3) Augusto de Lima foi recebido por Medeiros e Albuquerque no dia

(3) O Almirante Jacequai foi recebido por Afonso Arinos em 9 nov. 1907. 
e Albuquerque, que o receberá. Então este nos disse que na Camara se entenderá com o Orlando a ver se acham alguma combinação. Ia escrever-lhe isto mesmo, quando recebi a sua carta, a que ora respondo. Podemos encontrar-nos amanhã no Garnier.

Conto que haja passado bem, e espero se [ilegível] apresentar os meus respeitosos cumprimentos á Exm. Senhora D Flora. Creiame sempre, com a maior consideração.

Am ${ }^{0}$ ad ${ }^{\circ}$ r. obrido.

Machado de Assis

Napoles, 12 de Fevereiro de 1909.

\section{Presado Mestre e Confrade, Snr. Dr. Oliveira Lima}

Não posso resistir, depois de uma boa e conscienciosa leitura de seu livro, (1) ao desejo de escrever-lhe de novo, para lhe agradecer uma vez ainda o beneficio que elle me fez. E que esse generoso livro não só me ensinou cousas que eu não sabia, como tambem me ensinou a ver outras que eu suppunha conhecer perfeitamente, quando aliás nem sequer as tinha sabido ver $\mathrm{O}$ ambito de acção da Diplomacia vagamente se me afigurava um theatro especial, onde todas as peças eram sempre muito bem montadas e os respectivos figurantes muito bem vestidos e muito correctos, ainda que houvesse entre elles algum principe a fazer de clown, algum patife a fazer de santo, ou mesmo algum homem de espirito a fazer de tolo; desde porém que seu livro me abrio familiarmente a porta da caixa desse aristocratico theatro e eu vi como la dentro as cousas se arranjavam, perdi é verdade a primitiva illusão sobre certos protagonistas ou certos comparsas agaloados, e sorri maliciosamente, mas em compensação ganhei enthusiasmo pelo pessoal que não apparece ao publico e por isso mesmo não podia eu apreciar devidamente, e ao qual no fim de contas é devido o melhor do exito do espectaculo: pontos, contraregras, machinistas, scenographos e ensaiadores das cousas diplomaticas, só fiquei conhecendo e devéras estimando depois daquella feliz leitura, pois, mesmo que puxa-vistas, condemnado ao meu porão consular, não sabia do que ia lá por cima no palco, senão quando algum diabo, de mentira ou de verdade, descia de improviso pelo alçapão, acompanhado de risadas ou de imprecações, e a minha estonteada curiosidade tinha de contentar-se apenas com o rumor dos applausos ou da pateada vindo da plateia, o que, já se vê, não podia servir mui-

(1) Referência às Cousas diplomáticas. Lisboa, A Editora, 1908. 
to para me pôr ao corrente dos segredos das taes cousas diplomaticas. Mas o que de mais positivo ganhei logo com a leitura, foi o reconciliar-me com a carreira consular a que pertenço e ficar amando o meu emprego, como nunca o tinha amado até então, principalmente se remontarmos á triste epocha em que o providencial Rio Branco não havia ainda polido um pouco os arreios com que a nossa Secretaria encabrestava dantes a consulagem a seu cargo; outro lucro que com a leitura apanhei, não menos consolador, foi encontrar em "Cousas Diplomaticas", preceituados em regras definitivas e axiomaticas, certos protestos que eu ha muito sentia se formarem dentro de mimi e que, naturalmente por mingoa de cabedal de observação justa e por deficiencia de cultura apropriada, jamais chegára a formular, nem muito menos chegaria algum dia a enfeixar naquellas vigorosas syntheses de que se compõe o abençoado livro. E foi isto justamente o que neste, por outro lado, mais me encantou, foi esse poder spenseriano de reunir em diversos punhados de paginas, separados entre si mas ligados pela mais intima e perfeita cohesão, todos os aspectos de um mundo tão chaotico e sibylino, que eu, só de o presentir [sic] ou lobrigar do fundo do meu porão, sentia vertigens e me perturbava a ponto de me ser totalmente impossivel conciliar a previsão do que nelle eu imaginava com os meus consequentes raciocinios, quando em verdade o que me parecia impenetraveis nuvens de deozes nada mais era do que fumo de perfumados havanas, e os trovões olympicos, que tanto me intimidavam, não passavam de simples exclamações de prazer e estoirios de garrafas de champagne; atravez, entretanto, desse ruidoso nevoeiro de festa, comecei com grande surpreza minha, a distinguir, nitidamente definidos, vultos grandes, medios e pequenos da Diplomacia classica e moderna, e pude ver então como os diplomatas capazes trabalhavam ao lado da mandronice dos poseurs, sem jamais se embaraçarem uns aos outros, antes conservando entre si uma interessante harmonia de equilibrio, que, sem fazer o poseur menos futil, nem menos deligente o capaz, a arte temperava com certa dosita de pose e ao outro emprestava uns certos ares de utilidade pratica. E o melhor é que tudo isso vem dito e é ensinado sem a menor pretenção, sempre com a mesma elegante sobriedade de estylo e com um discreto humorismo, que não permitte aos labios do leitor desarmarem o sorriso com que elle virou a primeira pagina do livro, o que não impede aliás que o autor vá por ali afóra entestando com os mais tremendos pontos da sua escabrosa these, como se estivesse a tratar por desfastio das cousas mais simples e agradaveis deste mundo. É admiravel, não ha duvida!

Mas tambem, só um ministro pleniponenciario, folheado de um homem de espirito e escriptor de raça, poderia levar a cabo semelhante livro; se ao autor faltasse qualquer destas duas qualidades fundamentais, a obra não teria razão de ser: se elle não occupasse o mais alto 
posto na Carreira, passaria por despeitado, e se elle só dispozesse de estylo de protocollo ninguem lhe supportaria as asserções. Nunca vi nem li a tal celebre comedia "La Carrière", (2) que creou o morbus consularis, mas estou em affirmar que antes de "Cousas Diplomaticas" nenhum outro critico destapou e remexeu daquelle modo o caldeirão onde se cosinham os grandes e pequenos interesses da carreira, nem tão em evidencia o merito e demerito dos respectivos cosinheiros; porisso fico desde já bem convencido que desse livro, se por acinte não acertarem de o contrariar, hão de sahir, pelo menos entre nós, reformas não conseguidas até hoje pela boa vontade dos chefes, nem pelo bom desejo dos interessados immediactos, constituindo a esperança dessas reformas mais um outro beneficio da obra, que eu, na qualidade de consul, a ella naturalmente ficarei a dever E com effeito em "Cousas Diplomaticas" que pela primeira vez os excommungados agentes consulares são, a serio, trazidos á ribalta do privilegiado theatro; até aqui os infelizes eram apenas lembrados para despachar as malas particulares dos ministros em transito pelo logar do Consulado, ou então como materia de escarneo, servindo o seu misero titulo de nome para orangotangos.

Já vê, meu caro autor, que tenho razão de sobra para me sentir profundamente grato a esse seu livro extraordinario, a esse libello feito todo de lealdade e de altruista revolta, e que pois me seja relevado o mau-gosto destes elogios feitos assim á queima-roupa.

Questão de temperamento - eu não sei applaudir sem dar palmas e soltar bravos, mas o que a estes falta de bom-tom lhes sobra em sinceridade.

Admirador reconhecido e affectuoso

Aluizio Azevedo

(2) La Carrière é de Abel Hermant (Paris, 1862; Chantilly, 1950) e foi apresentado no Gimnase de Paris em 17 mar. 1897.

Abel Hermant passou pelo Naturalismo de Zola e pelo psicologismo de Paul Bourget. Revelou-se também na sátira de costumes, na observação do mundo elegante e aristocrático e na apreensão da atualidade imediata. Em 1944, Abel Hermant foi expulso da Academia Francesa acusado de colaboracionismo. (Cf. Enciclopedia dello Spettacolo. Roma, Casa Editrice Le Maschere /1959/ Vol. VI.) 